\author{
Cadernos de \\ ESTUDOS LINGǘssT(C) - (54.1), Campinas, Jan./Jun. 2012
}

\title{
GESTICULAÇÃO E FLUÊNCIA: CONTRIBUIÇÕES PARA A AQUISIÇÃO DA LINGUAGEM
}

\author{
MARIANNE CARVALHO BEZERRA CAVALCANTE ${ }^{1}$ \\ LAVÍNIA WANDERLEY PINTO BRANDÃO²
}

\begin{abstract}
RESUMO
Neste artigo buscamos discutir o papel da gesticulação no processo aquisicional, como uma das primeiras pistas de fluência na fala de forma a contribuir para uma proposta multimodal de compreensão da aquisição da linguagem. Partimos da premissa de que gesto e fala formam uma única matriz cognitiva, para isso nos embasamos em autores como Kendon (1992), McNeill (1985) entre outros. Já que a gesticulação dentro da proposta de Kendon (1992) envolve os gestos que emergem ao longo do fluxo da fala, tendo a função de garantir sua continuidade. Almejamos, assim, destacar os primeiros indícios de gesticulação em aquisição da linguagem, de forma a compreender este processo de emergência da fluência e da gesticulação, pondo em discussão também as terapias de linguagem tradicionalmente realizadas com sujeitos surdos implantados.

Palavras-Chave: gesticulação; fluência; aquisição da linguagem.
\end{abstract}

\begin{abstract}
In this article we discuss the role of gestures in the acquisition process, as one of the first clues of fluency in speech in order to contribute to an understanding of the proposed multimodal language acquisition. We start from the premise that gesture and speech form a single cognitive matrix (Kendon, 1992; McNeill ,1985). Gestures emerge along the flow of speech, and have the function to ensure its continuity. We aim to highlight the first signs of gestures in language acquisition, in order to understand this process of emergence of fluency and gesturing, also extending the discussion to language therapies traditionally performed with cochlear-implanted deaf subjects.
\end{abstract}

Keywords: gestures; fluency; language acquisition.

\section{A MATRIZ GESTO E FALA ${ }^{3}$}

A perspectiva de McNeill (1985) propõe que gesto e fala se encontram integrados numa mesma matriz de produção e significação, afirmando que " $a$

1. UFPB/CNPq. João Pessoa (PB), Brasil. Bolsista CNPq/PQ processo no 306013/2009-6. e-mail: marianne.cavalcante@gmail.com

2. UFPB/FCM. João Pessoa (PB), Brasil. e-mail: laviniabrandao@uol.com.br

3. A discussão presente neste tópico foi abordada no artigo Gesture and speech in mother-baby interactions: Characterizing first linguistic uses. In: SCLIAR-CABRAL, L. (Org.), Psycholinguistics: Scientific and technological challenges. Porto Alegre: EDIPUCRS, 2010, pp. $173-181$. 
ocorrência de gestos ao longo da fala implica que durante o ato de fala dois tipos de pensamento, imagístico e sintático, estão sendo coordenados” (p. 11). Isto é, são constitutivos de um único sistema linguístico.

Kendon (2000) afirma que a investigação sobre gestos dentro de uma perspectiva linguística pouco se desenvolveu e, com a reorientação da Linguística ocorrida sob a influência de Chomsky, que trouxe os estudos linguísticos para uma espécie de ciência mental, fez com que os aparentes e desaparecidos interesses no estudo da linguagem gestual fossem novamente reunidos enquanto um tópico de inquirição (KENDON, 1982). E, sendo uma real consequência da análise da língua enquanto parte de uma ciência mental, com ênfase nos estudos dos processos cognitivos, hoje são revigorados os estudos dos gestos por parte daqueles que se interessam pelo estudo da língua. Assim, se a língua é posta como uma atividade cognitiva e, se as expressões gestuais estão intimamente envolvidas em atos da expressão linguística falada, então parece razoável observar os gestos mais aproximados do campo das atividades cognitivas. Isto fundamenta uma nova forma de pôr e analisar a questão do relacionamento existente entre os gestos e a língua (KENDON, op. cit. p. 49).

Percebe-se que Kendon (op. cit.) situa o estudo dos gestos enquanto atividade cognitiva. Apesar da relevância dos trabalhos pioneiros do autor e do enfoque cognitivista a eles atribuído, nesta pesquisa privilegiaremos uma perspectiva interacionista ${ }^{4}$; nesta direção há pesquisas como a de Laver (2000).

Laver (op. cit.) ressalta a importância do gesto no processo interativo. De acordo com o autor, ao analisarmos qualquer comportamento comunicativo, é fundamental que compreendamos a relação entre abstrações idealizadas da intenção comunicativa e as variações das realizações físicas detalhadas de cada indivíduo e entre indivíduos. Ou seja, a diferença entre o que foi idealizado para a comunicação e o que realmente acontece. Destaca ainda que, embora haja gestos comuns a uma comunidade falante, tais gestos variam de pessoa para pessoa e há, ainda, fatores intrapessoais que afetam cada indivíduo e precisam ser considerados quando se faz uma descrição de uma interação.

Buscando uma definição para gesto, McNeill (2000, p. 1) afirma ser este um termo que necessita explanação, uma vez que não temos gesto no singular, mas gestos. Ele afirma que prefere o termo no plural, pois há diversos momentos em que precisamos distinguir movimentos corriqueiramente nomeados de gestos. Assim, o autor apresenta um contínuo para vários movimentos chamados de gestos, elaborado por Kendon (1982) e é conhecido como o "contínuo de Kendon"5.

Os gestos que formam este contínuo são: a gesticulação; a pantomima; os

4. Como destaca Morato (2004) na linguística a noção de interação é bastante polissêmica. Na aquisição da linguagem temos desde uma vertente caracterizada pelos trabalhos de Vygotsky (1979) e Bruner $(1975,1983)$, privilegiando o aspecto da mediação e a natureza das atividades interativas na relação adulto-criança; até o interacionismo representado pelos trabalhos de De Lemos (1992, 1995), que contempla a interação como o espaço da estrutura em que comparece a criança como sujeito falante, o outro como representante da língua e própria língua em funcionamento.

5. 'Kendon's continuum". 
emblemas; a(s) língua(s) de sinais. A gesticulação caracteriza-se como o conjunto de gestos que acompanham o fluxo da fala, envolvendo braços, movimentos de cabeça e pescoço, postura corporal e pernas, possui marcas da comunidade de fala e marcas do estilo individual de cada um; a pantomima são gestos que 'simulam' ações ou personagens executando ações, é a representação de um ato individual, tem um caráter de narrativa, pois envolve uma sequência de micro ações; os emblemas ou gestos emblemáticos são aqueles determinados culturalmente (são convencionais) tais como o uso, em nossa cultura, do gesto que envolve a mão fechada e polegar levantado significando aprovação; a língua de sinais enquanto sistema linguístico próprio de uma comunidade.

Kendon (1982) organiza seu contínuo a partir de quatro relações estabelecidas entre gesto e fala: relação com a produção de fala (1); relação com as propriedades linguísticas (2); relação com as convenções (3), relação com o caráter semiótico (4), conforme tabela a seguir:

\begin{tabular}{|l|l|l|l|l|}
\hline & Gesticulação & Pantomima & Emblemáticos & Língua de sinais \\
\hline Contínuo 1 & $\begin{array}{l}\text { Presença } \\
\text { obrigatória de fala }\end{array}$ & Ausência de fala & $\begin{array}{l}\text { Presença } \\
\text { opcional de fala }\end{array}$ & Ausência de fala \\
\hline Contínuo 2 & $\begin{array}{l}\text { Ausência de } \\
\text { propriedades } \\
\text { linguísticas }\end{array}$ & $\begin{array}{l}\text { Ausência de } \\
\text { propriedades } \\
\text { linguísticas }\end{array}$ & $\begin{array}{l}\text { Presença } \\
\text { de algumas } \\
\text { propriedades } \\
\text { linguísticas }\end{array}$ & $\begin{array}{l}\text { Presença de } \\
\text { propriedades } \\
\text { linguísticas }\end{array}$ \\
\hline Contínuo 3 & Não convencional & $\begin{array}{l}\text { Não } \\
\text { convencional }\end{array}$ & $\begin{array}{l}\text { Parcialmente } \\
\text { convencional }\end{array}$ & $\begin{array}{l}\text { Totalmente } \\
\text { convencional }\end{array}$ \\
\hline Contínuo 4 & Global e sintética & $\begin{array}{l}\text { Global e } \\
\text { analítica }\end{array}$ & $\begin{array}{l}\text { Segmentada e } \\
\text { analítica }\end{array}$ & $\begin{array}{l}\text { Segmentada e } \\
\text { analítica }\end{array}$ \\
\hline
\end{tabular}

Extraído de McNeill (2000, p.5)

Se analisarmos os tipos de gestos dentro dos contínuos da esquerda para a direita(Gesticulação-Pantomimas - Emblemáticos - Língua de Sinais) percebemos que: a presença obrigatória de fala diminui; a presença de propriedades linguísticas aumenta; os gestos individuais são substituídos por aqueles socialmente regulados.

Como se observa, há muito a dizer a respeito da relação gesto e fala enquanto matriz de significação, discussão que vem se colocando para a Linguística a partir do momento em que a fala e a oralidade têm se destacado nas pesquisas atuais.

Neste sentido, entendemos por fala toda forma de produção discursiva para fins comunicativos na modalidade oral (situa-se no plano da oralidade), sem a necessidade de uma tecnologia além do aparato disponível pelo próprio ser humano. Caracteriza-se pelo uso da língua na sua forma de sons articulados e significativos, bem como aspectos prosódicos e uma série de recursos expressivos de outra ordem: gestualidade, movimentos corporais, mímica (MARCUSCHI, 2005). 
A fala em sua caracterização é concebida na sua relação com recursos de outra ordem, como salienta Marcuschi (op. cit.). Isto é, a fala integra outras modalidades, caracterizando-se enquanto multimodal. É justamente esta a perspectiva que norteará este artigo.

\section{GESTO E FALA EM AQUISIÇÃO DA LINGUAGEM - UM PERCURSO}

Na aquisição da linguagem, autores como Bruner $(1975,1983)$ dedicaramse ao estudo da relação entre gesto e fala, mas concebendo-o como modalidades comunicativas de períodos distintos na aquisição da linguagem. Assim, o uso do gesto seria característico do chamado período pré-linguístico da criança e desapareceria em função da emergência da fala, do sistema linguístico. Outros autores também seguiram esta premissa do gesto "guardar o lugar" para fala remetendo a um primitivismo gestual, tais como os trabalhos clássicos de Bates; Camaioni; Volterra (1979); Bates; O’Connell; Shore (1987), que defendiam a vinculação do gesto de apontar e de outros gestos, no período de transição para a linguagem, como precursores dos performativos da língua (declarativos e imperativos). Tais gestos recebem a seguinte nomenclatura: protodeclarativos $e$ proto-imperativos. Os denominados protodeclarativos são caracterizados quando a criança destaca um objeto no mundo para seu parceiro. Os proto-imperativos são caracterizados quando a criança usa o adulto para obter um dado objeto. A emergência de gestos protodeclarativos e proto-imperativos é notada quando a criança começa a entender que suas próprias ações não são a origem de todos os eventos no mundo.

A caracterização destes comportamentos gestuais como protodeclarativos ou proto-imperativos estão inseridos no ato interativo. Segundo Dore (1979) sua caracterização é determinada a partir da interpretação dada pelo parceiro adulto ao comportamento gestual deflagrado pela criança. Desta forma, o "status" do comportamento deflagrado vai depender da interpretação que o adulto der a ele.

Seguindo uma perspectiva interacionista, desenvolvemos uma pesquisa discutindo a natureza do gesto de apontar na aquisição da linguagem ${ }^{6}$ (CAVALCANTE, 1994). O objetivo consistia na compreensão do gesto de apontar enquanto elemento dêitico fundamental no estabelecimento da referência linguística nas interações mãe-criança. Assim, através de uma investigação longitudinal acompanhamos uma díade mãe-bebê ao longo dos primeiros vinte e quatro meses de vida da criança, percorrendo desde o uso assistemático do gesto de apontar e a emergência de 'morfologias gestuais', até sua ritualização, visando à topicalização de referentes na dialogia mãe-bebê.

No entanto, os trabalhos acima citados têm atribuído à gestualidade um caráter pré-linguístico, ou seja, os gestos seriam anteriores e primitivos em relação à língua. Além disso, ainda não propunham uma articulação entre gesto e fala

\footnotetext{
6. O Gesto de apontar como processo de co-construção na interação mãe-criança. Dissertação de mestrado inédita, [sob a orientação de L. A. Marcuschi]. UFPE, Recife, 1994.
} 
Cadernos de EsTUDOS Lingǘlsticos (54.1) - Jan./Jun. 2012

na aquisição da linguagem, tal como vem sendo desenvolvido por autores como Goldin-Meadow e colaboradores (BUTCHER \& GOLDIN-MEADOW; 2000; GOLDIN-MEADOW, 1993; GOLDIN-MEADOW, ALIBALI \& CHURCH, 1993; MCNEILL, 1985; 2000).

Nos últimos cinco anos temos trabalhado a partir da concepção da matriz gesto e fala (CAVALCANTE 2006; 2009a; 2009b; 2009c; 2010a; 2010b; ARAGÃO \& CAVALCANTE, 2009a; COSTA FILHO \& CAVALCANTE, 2009b; MAIA \& CAVALCANTE, 2009c). Isto nos tem possibilitado mapear a emergência dos gestos na primeira infância, articulado com a produção de fala em situações interativas diádicas, o que tem nos permitido, cada vez mais, nos afastarmos de uma concepção de primitivismo gestual e de seu caráter prélinguístico. Isto é, defendemos a perspectiva de que os gestos não guardam o lugar da fala na aquisição da linguagem, seu estatuto não seria pré-linguistico. Ao invés disso, consideramos o gesto como co-participe, já que ele constitui a matriz da linguagem.

\section{GESTICULAÇÃO E ALTERAÇÕES DE LINGUAGEM}

O estudos acerca da gestualidade tem sido explorados nos trabalhos acerca das alterações de linguagem (FEDOSSE, 2000; LAVER, 2000; SANTANA ET AL., 2008). Santana et al. (2008) destacam que Liepman (1900) ao deter-se acerca das pertubações dos gestos (apraxias) em sujeitos afásicos já estabelecia relações entre as duas alterações: apraxia e afasia - enquanto alterações cognitivas.

Na neuropsicologia cognitiva há estudos que apontam similaridades na forma como o cérebro processa a produção verbal e os gestos, tais como Carrilho (1996) apontado por Santana et al. (2008). Além disso, nas afasias - tanto a de produção quanto a de compreensão - há impacto na atividade gestual. Logo, a classificação tradicional das apraxias do sistema motor afetado: apraxia de membros, motoras, de fala, verbal, etc. seria inadequada, já que gesto e fala formam uma matriz, tal como salienta Fedosse (2000).

Como se observa a relação do gesto com a produção de fala tem sido foco de pesquisas na área da neuropsicologia assim como na linguística. Daí a importância em tentar compreender como se inicia este processo na aquisição da linguagem. Estabelecer o papel da gesticulação no início do período aquisicional permitirá também pensar o seu papel nas terapias fonoaudiológicas com pacientes implantados, por exemplo, uma vez que tais terapias tradicionalmente estão centradas em metodologias auriorais, em que a percepção auditiva - que vem em primeiro plano - e a produção oral são o foco dos processos terapêuticos (BRANDÃO, 2010). E, muitas vezes, pelo dimensionamento dado à relação percepção/produção sonora, deixa-se de lado o processo aquisional de uma forma mais ampla e a entrada da criança implantada no plano da interlocução com fluxo de fala, que vem muito tardiamente. 
CAVALCANTE e BRANDÃO - Gesticulação e fluência: contribuições...

Vejamos o fragmento $^{7}$ abaixo que ilustra a interação mãe-bebê surdo implantado:

Fragmento 1: A mãe e a criança estão brincando com as peças de um jogo de encaixe. A criança tem 36 meses.

C.: ãieiiii eeeeee ( vocalizando alto, tentando pegar a peça).

M.: Peça. Me dá! Você sabe dizer me dá direitinho.

(Afastando a peça para que a criança não consiga pegar.)

M.: você quer o quê? (Olhando para a criança)

C.: (Pega uma cebolinha de borracha.)

M.: que é isso? (Olhando para a criança)

(...)

M.: É o miau. MIAU. Olha o gatinho. (Apontando também)

C.: EEEeeeee (Passa a página do livro, olha para a mãe apontando para figura)

M.:O PEIXE. É o peixinho. OLHA o peixinho. (Olhando para a criança)

Neste fragmento de interação mãe-bebê temos a presença de um processo permeado por uma fala diretiva materna centrada em salientar itens lexicais para o bebê, tal como propõe a terapia aurioral. Um momento como este não é característico apenas dos contextos com crianças surdas implantadas, também na interação com crianças sem acometimentos auditivos encontramos usos de fala diretiva destacando palavras para criança repetir.

No entanto, tal como Brandão (2010) mostra, este é o formato das interações desta díade específica pós implante coclear. Como salienta a autora (op. cit.) após o treinamento materno na metodologia aurioral, que privilegia o acesso sonoro e desencoraja a produção gestual infantil, sob a justificativa de que ancorada no gesto a criança não se inserirá na produção verbal, a mãe torna-se mais diretiva, preocupando-se em nomear objetos enfaticamente para a criança.

Assim, as interações dialógicas entre mãe e criança tornam-se pouco extensas, já que se resumem a uma estrutura voltada para perguntas polares "o que é X?", ou enfatizar itens para serem repetidos, como vimos no fragmento anterior. Além disso, é perceptível neste fragmento e nos comentários de Brandão (2010) o quanto o desconhecimento do papel dos gestos como co-partícipes do processo aquisicional pode ser um elemento dificultador da entrada da criança na linguagem.

\section{FLUÊNCIA E AQUISIÇÃO DA LINGUAGEM}

Segundo Almeida (2009) há um consenso em tomar a fluência como uma medida de desempenho na língua, salientando, a partir de Scarpa (1995) que

7. Este fragmento compõe o corpus da tese de Brandão (2010): Interação mãe-bebê surdo implantado: entre o 'ouvinte suposto' e o 'aprendiz de ouvinte', PROLING, João Pessoa, PB. 
este conceito sempre foi definido pela sua oposição, isto é, pelo que venha a ser disfluente. Neste sentido, o sujeito fluente seria uma abstração ideal que inexiste, mas que é necessária para que possamos investigar a linguagem.

$\mathrm{Na}$ perspectiva de Merlo (2006) o discurso fluente envolve algumas características tais como: (a) baixa frequência de hesitações; (b) baixa frequência de reformulações; (c) baixa frequência, curta duração e uso nativo de pausas silenciosas fluentes; (d) taxa de elocução (speech rate) confortável; (e) facilidade de emissão; (f) habilidade gramatical; (g) diminuição da complexidade semântica.

Observa-se que tais características apontam para um modelo de falante proficiente em sua língua materna e no caso das crianças, como perceber as pistas que contribuirão para a construção da fluência?

Adotando a perspectiva de Scarpa que concebe os trechos de fala fluente como

\footnotetext{
"os já ajeitados, conhecidos, analisados ou, na grande maioria dos casos, congelados, vêm em bloco. Os disfluentes são aqueles em construção, instáveis, com tentativas infrutíferas de segmentação em blocos prosódicos; supõem passos mais complexos tanto paradigmática quanto sintagmaticamente na elaboração do enunciado." (SCARPA, 1985, p.171)
}

Quer dizer, relacionando aos momentos aquisicionais, haveria fluência infantil nos trechos de fala já cristalizados na fala infantil. Por estarem presentes nas expressões formulaicas e fragmentos cristalizados da fala infantil, a autora constata sua presença a partir dos dois anos de idade na fala infantil, quando emergem estas estruturas ao longo da produção de fala. Já a disfluência estaria presente nas tentativas de conversão do discurso direto em indireto, nas tentativas de relatos pessoais, em início de tópico conversacional ou quando a criança tenta responder com expressões não-cristalizadas a perguntas polares (RAMOS; SCARPA 2007)

As autoras (op. cit.) destacam a relação da fluência e os enunciados cristalizados, destacando que este é o período em que a criança encontra-se sob o domínio do discurso materno ou traz a em sua fala a presença de holófrases.

Trazemos aqui um fragmento de narrativa infantil em que se percebe tal funcionamento.

\section{R.: Era uma vez o sapeuzinho vermelho ia na folesta}

(inspiração) e:... (pausa hesitante) [(SI)]

M.:[(SI)] continua. e ele contô o lobo:... (pausa) o lobo e/e e... (repetição hesitante) depois sabe que o lobo ia fazê? Pegô o revolve dele e matá... (pausa) matá o sapeuzinho e depois... (pausa)

M. : Fala, conta.

R.: e depois a ota pequenininha minha filha foi lá na flo (SI)

na flolesta também (inspiração) e eu encontei o lobo

(Extraído de RAMOS; SCARPA, 2007, p. 357). 
CAVALCANTE e BRANDÃO - Gesticulação e fluência: contribuições...

Este fragmento acima ilustra bem a relação fluência e disfluência na fala infantil, em que os trechos fluentes seriam aqueles que envolveriam blocos cristalizados da história narrada e os momentos em que há hesitações e pausas aqueles em que a criança desenvolve formulações acerca da história narrada.

Mas este é somente um lado das questões que envolvem a fluência. A narrativa oral está ancorada em movimentos gestuais que constroem a narrativa. No caso do fragmento acima temos acesso apenas ao material publicado pelas autoras que corresponde à transcrição da produção verbal, aí incluídas marcas prosódicas como as pausas, hesitações etc. É justamente buscando ilustrar a emergência da gesticulação no processo aquisicional que trazemos análise de dados videografadas de interações naturalísticas mãe-bebê que mostram as primeiras gesticulações infantis.

\section{QUANDO A GESTICULAÇÃO COMEÇA?}

Não podemos fazer uma discussão acerca da gesticulação no processo aquisicional sem levar em consideração os demais gestos que compõem o contínuo gestual. Assim, ao longo do processo aquisicional temos a presença de gesticulação, pantomima e emblemas. No levantamento feito em duas díades mãebebê $(\mathrm{B} ; \mathrm{C})$ encontramos a emergência das primeiras gesticulações a partir dos sete meses de vida das crianças, tal como mostram os quadros abaixo:

\begin{tabular}{|c|c|c|c|}
\hline \multicolumn{4}{|c|}{ QUANTIFICAÇÃO DOS GESTOS USADOS PELA CRIANÇA DA DÍADE B } \\
\hline IDADE & GESTICULAÇÃO & EMBLEMA & PANTOMIMA \\
\hline 07 M E 06 DIAS & 01 & 02 & $*$ \\
\hline 07 M E 24 DIAS & $*$ & $*$ & $*$ \\
\hline 08 M E 14 DIAS & 08 & 05 & $*$ \\
\hline 09 M E 20 DIAS & 02 & 04 & $*$ \\
\hline 10 M E 05 DIAS & $*$ & 01 & $*$ \\
\hline 11 M E 06 DIAS & $*$ & 02 & $*$ \\
\hline 12 M E 27 DIAS & 02 & 06 & 03 \\
\hline 13 M E 19 DIAS & 04 & 05 & $*$ \\
\hline 14 M E 21 DIAS & $*$ & 02 & $*$ \\
\hline 15 M E 04 DIAS & 02 & 02 & 02 \\
\hline 15 M E 20 DIAS & $*$ & 06 & $*$ \\
\hline 16 M E 09 DIAS & $*$ & 10 & $*$ \\
\hline 17 M E 13 DIAS & $*$ & 12 & 01 \\
\hline
\end{tabular}

Quadro 1: Gestos Infantis díade B

A criança da díade B fez uso, algumas vezes, da gesticulação quando balançava os braços, levantava as mãos, ou quando balbuciava e mexia os braços de forma desordenada. O uso dos emblemas, principalmente do gesto do apontar ou de ações como dar e pegar, mostrar e pedir, parece ter sido privilegiado aos $16 \mathrm{e}$ 
17 meses, o que também não implica que não tenha emergido antes dessa idade. A pantomima foi o tipo de gesto menos utilizado pelo bebê na faixa etária analisada por nós, tendo indícios aos 12, 15 e 17 meses.

\begin{tabular}{|c|c|c|c|}
\hline \multicolumn{5}{|c|}{ QUANTIFICAÇÃO DOS GESTOS USADOS PELA CRIANÇA DA DÍADE C } \\
\hline IDADE & GESTICULAÇÃO & EMBLEMA & PANTOMIMA \\
\hline 07 M E 09 DIAS & $*$ & 01 & $*$ \\
\hline 08 M E 08 DIAS & 02 & 02 & 02 \\
\hline 09 M E 10 DIAS & 03 & 05 & $*$ \\
\hline 10 M E 15 DIAS & 06 & 13 & 03 \\
\hline 11 M E 24 DIAS & 01 & 05 & 03 \\
\hline 12 M E 12 DIAS & 07 & 08 & 05 \\
\hline 14 M & 01 & 16 & 11 \\
\hline 15 M & 01 & 14 & 05 \\
\hline 16 M & 01 & 14 & $*$ \\
\hline 17 M & $*$ & & 05 \\
\hline
\end{tabular}

Quadro 2: Gestos infantis díade C

A criança em questão apresenta a gesticulação quando levanta os braços ao balbuciar, bate as mãos uma na outra de forma desordenada, balança os braços, etc. A tabela acima nos mostra que o maior uso da gesticulação deu-se aos 10 e aos 12 meses de vida do infante. Os emblemas foram usados em uma maior proporção aos 10 meses, aos 15, 16 e 17 meses, principalmente em contextos que exigiam as ações de dar e pegar, mostrar e apontar tanto em direção a locais como em direção a gravuras de revistas e livros. A pantomima pôde ser verificada em quase todas as idades analisadas tendo seu uso privilegiado aos 10 e aos 16 meses.

A partir dos quadros mostrados acima, fica claro que as produções infantis estão predominante ancoradas na produção de gestos emblemáticos, principalmente o apontar, característica que a literatura em aquisição da linguagem já vem demonstrando ao longo do tempo (BATES, CAMAIONI \& VOLTERRA, 1979; BATES, O’CONNELL \& SHORE, 1987; CAVALCANTE, 1994).

Como a gesticulação depende do fluxo de fala, esta tem seu uso pontual, visto que no período aquisicional levantado predominam os balbucios e holófrases, como mostraremos a seguir. Mas mesmo assim estas produções verbais se fazem acompanhar da gesticulação, que tal como propomos neste artigo faz parte de uma mesma matriz cognitiva junto com a fala.

Os fragmentos abaixo ilustram este funcionamento:

Fragmento 1: Díade B, idade do bebê: 9 meses e 2dias. (0; 09;02)

M.: Cadê mãmãe Tu? Cadê mãezinha? Êêe meu lindo! Psiu!

B.: Êen (balbucia mexendo os bracinhos)

M.: Êêe...Cadê Vitinho? Achô! Cadê meu lindinho? Cadê? Cadê? Psiu! Vitor...? 
O fragmento acima ilustra os primeiros esboços de gesticulação que surgem aliados à produção do balbucio infantil. Quer dizer, a produção verbal infantil embrionária para se sustentar necessita da produção gestual que tem a duração concomitante ao tempo de produção do balbucio.

Fragmento 2: Díade C, idade 12 meses $(0 ; 12 ; 00)$.

C.: Oua! Ah! Hum! (Balbucia com um dos braços levantados sem olhar para mãe, enquanto anda em direção à câmera)

M.: Sim mamãe diga!

Neste fragmento há o reconhecimento da produção discursiva do bebê pela mãe quando ela atribui sentido à produção infantil. Vale salientar que o bebê faz a produção gestuo-vocal sem olhar para mãe, mas sim dirigindo-se para a câmera.

Fragmento 3: Díade C, idade $34 \mathrm{~m}$ e 17 d. $(0,0 ; 34 ; 17)$.

M.: Jogou bola, né?

C.: $\quad$ Na casa (responde olhando para a câmera e depois para a mãe, enquanto levanta rapidamente o braço direito)

M.: na qua:dra gran:.de, grandona a quadra.

C.: É..! uma bem gondona assim (A criança fala e ao mesmo tempo estica os braços para os lados simulando o tamanho da quadra).

Observamos aqui a presença da gesticulação nos dois turnos de fala da criança; no primeiro, há um esboço rápido de gesticulação para ilustrar sua produção verbal, e no segundo turno da criança, a gesticulação tem a função de ilustrar o dimensionamento da quadra, tal como a literatura tem descrito o funcionamento da gesticulação.

Os três fragmentos ilustram o processo de constituição inicial da gesticulação nas interações mãe-bebê, mostrando como esta vai se constituindo aliada às produções vocais infantis, ao longo do tempo.

Privilegiar estritamente a produção verbal como sendo a única instância de realização do processo aquisicional é limitar a compreensão do processo como um todo. Há, portanto, a necessidade de considerar este processo enquanto multimodal, em que diversos elementos co-atuam para que as interações linguísticas aconteçam e promovam a passagem do infante à falante/usuário de sua língua.

Uma postura deste tipo permite também compreender melhor as alterações de linguagem tais como as apraxias, ao desmistificar suas divisões enquanto motoras ou verbais, tal como propõe Fedosse (2000), como também, promover nas terapias de linguagem com surdos implantados estratégias que envolvam o uso dos gestos, já que estes são co-autores do processo linguístico, contribuindo para o processo efetivo de inserção destes sujeitos no processo aquisicional. Esperamos assim, que este olhar acerca da relação entre gesticulação e fluência venha a possibilitar uma re-significação do que chamamos tradicionalmente de aquisição da linguagem. 


\section{REFERÊNCIAS BIBLIOGRÁFICAS}

ALMEIDA, V. B. (2009). Pausas preenchidas e domínios prosódicos: evidências para a validação do descritor fluência em um teste de proficiência oral em língua estrangeira. In: Alfa, São Paulo, 53 (1): 167-193.

ARAGÃO, A. L.; CAVALCANTE, M. C. B. (2009). Um panorama da construção gestual do bebê ao longo do primeiro ano de vida. In: VI Congresso Internacional da ABRALIN, João Pessoa. Anais da ABRALIN 40 anos. João Pessoa: Idéia, 2009a. v. 1. p. 214-220.

BATES, E.; CAMAIONI, L. \& VOLTERRA, V. (1979). The Acquisition of Performatives Prior to Speech, In: E. OCHS \& B. B. SCHIEFFELIN, (org.) Developmental Pragmatics, London, Academic Press.

BATES, E., O’CONNELL, B., \& SHORE, C. (1987). Language and communication in infancy. In J. OSOFSKY (Ed.), Handbook of infant development. New York: Wiley, 149-203,

BRUNER, J. (1975). The ontogenesis of speech acts. In: Journal of child language. Vol.2 No 1. Cambridge: Cambridge University Press.

. (1983). Childs Talk. Oxford University Press.

BRANDÃO, L. W. P. (2010). Interação mãe-bebê surdo implantado: entre o "ouvinte suposto" e o "aprendiz de ouvinte". Tese de doutorado. Programa de Pós-graduação em Linguística. UFPB, João Pessoa, PB.

BUTCHER, C.; GOLDIN-MEADOW, S. (2000). Gesture and the transition from one-to-two-word speech: when hand and mouth come together. In: D. MCNEILL, (ed.) Language and gesture. Spain: Cambridge University Press.

CAVALCANTE, M. C. B. (1994). O gesto de apontar como processo de co-construção nas interações mãe-criança. Dissertação de Mestrado. UFPE.

M. C. B. (2009a). A matriz gesto-fala em aquisição da linguagem: observando o diálogo em manhês. In: vi congresso internacional da ABRALIN, 2009, João Pessoa. Anais da ABRALIN 40 anos. João Pessoa : Idéia, v. 1. p. 2425-2434.

. M. C. B. (2009b). Gesto e voz: envelope afetivo de acesso ao simbólico na matriz relacional mãe-bebê. In: de Oliveira, E. F. L.; Ferreira, S. S.; Barreto, T. A.. (Org.). As interfaces da clínica com bebês. 1 ed. Recife: Bagaço, v. , p. 229-240.

. M. C. B. (2009c). Rotinas interativas mãe-bebê: constituindo gêneros do discurso. Investigações (Recife), v. 21, p. 153-170.

M. C. B. (2010a). (orgs.) Aquisição da linguagem em multimodalidade. 1ed. João Pessoa: Ed. da UFPB, p. 158.

M. C. B. (2010b). Matriz gesto e fala na dialogia mãe-bebê: esboços de gêneros do discurso. In. Cavalcante, M. C. B.; Faria, E. M. B. de; Leitão, M. (orgs.) Aquisição da Linguagem e Processamento Linguístico. João Pessoa: Ed. da UFPB, p. 158.

M. C. B. (2010c). Gesture and speech in mother-baby interactions: Characterizing first linguistic uses. In: SCLIAR-CABRAL, L. (Org.), Psycholinguistics: Scientific and technological challenges. Porto Alegre: EDIPUCRS, pp. 173 - 181.

CARRILHO, P. E. M. (1996). Apraxias Ideomotora e ideatória. Em Nitrini, P., Caramelli \& L. Mansur (Orgs.), Neuropsicologia: das bases anatômicas à reabilitação. São Paulo. p. 259-274.

COSTA FILHO, J. M. S.; CAVALCANTE, M. C. B. (2009). Cenas de atenção conjunta: uma análise sobre o foco do olhar. In: VI Congresso Internacional da ABRALIN, 2009b, João Pessoa. Anais da ABRALIN 40 anos. João Pessoa : Idéia, v. 1. p. 2096- 3001. 
CAVALCANTE e BRANDÃO - Gesticulação e fluência: contribuições...

DE LEMOS, C. T. G. (1992). Los processos metafóricos y metonímicos como mecanismos del cambio. Substratum, vol.1, n. 1 .

(1995). Língua e discurso na teorização sobre aquisição da linguagem. Letras de hoje, no. 4.

DORE, J. (1979). Conversational Acts and the Acquisition of Language. In: E. OCHS E B. . SCHIEFFELIN (org.) Developmental Pragmatics, London. Academic Press.

FEDOSSE, E. (2000). Da relação linguagem e praxia: estudo neurolinguístico de um caso de afasia. Dissertação de Mestrado. Instituto de Estudos da Linguagem da Unicamp, Campinas.

GOLDIN-MEADOW, S. (1993), When does gesture become language? A study of gesture used as a primary communication system by deaf children of hearing parents". IN K.R. GIBSON \& T. INGOLD (eds), Tools,Language and Cognition in Human Evolution. Cambridge, England: Cambridge University Press.

GOLDIN-MEADOW, S., ALIBALI, M., CHURCH R. B. (1993). Transitions in concept acquisition: Using the hands to read the mind. Psychological Review 100 (2): 279-297.

KENDON, A. (1982). The Study of Gesture: some remarks on its history. Recherches sémiotiques/ semiotic inquiry 2: 45-62.

. (2000). Language and Gesture: Unity or Duality? In D. MCNEILL, (ed.) Language and Gesture, Cambridge University Press: Cambridge, UK. p. 47-63.

LAVER, J. (2000). Unifying principles in the description of voice, posture and gesture. In: CAVE, C.; GUAITELLA, I. Interations et comportement multimodaux dans la communication. Paris, L'Harmattan.

MAIA, J. C.; CAVALCANTE, M. C. B. (2009c). Aquilo que precede a fala e não pode ser excluído da terapia de linguagem. In: VI Congresso Internacional da ABRALIN, 2009, João Pessoa. Anais da ABRALIN 40 anos. João Pessoa : Idéia, v. 1. p. 2183-2187.

MARCUSCHI, L. A. (2005). Oralidade e Letramento como práticas sociais. In MARCUSCHI, L. A e DIONISIO, A. P. (Orgs.) Oralidade e Escrita. Belo Horizonte, Autentica/MEC/CEEL.

MCNEILL, D. (1985). So you think gestures are nonverbal?. Psychological Review. Vol 92(3) 350371, Jul.. . (2999). Introduction. In: MCNEILL, D. (ed.) Language and Gesture. Cambrige University Press, Cambridge, UK.

MERLO, S. (2006). Hesitações na fala semi-espontânea: análise por séries temporais. 2006. 218 f. Dissertação (Mestrado em Linguística) - Instituto de Estudos da Linguagem, Universidade de Campinas, Campinas.

MORATO, E. M. (2004). O interacionismo no campo linguístico. In: MUSSALIM, F. ; BENTES, A. C. (Orgs.). Introdução à linguística: fundamentos epistemológicos, Vol. 3. São Paulo: Cortez.

RAMOS, S. ; SCARPA, E. M. (2007). Hesitações e rupturas em Aquisição da Linguagem: processos reorganizacionais na fala infantil. Estudos Linguísticos (São Paulo), v. XXXVI, p. 354-360.

SANTANA, A. P.; GUARINEllO, A. C.; BERBERIAN, A. P.; MASSI, G. (2008). O estatuto simbólico dos gestos no contexto da surdez. Psicologia em Estudo, Maringá, v. 13, n. 2, p. 297-306, abr./jun.

SCARPA, E. M. (1995). Sobre o sujeito fluente. Cadernos de Estudos Linguísticos, Campinas, v.29, p.163-184. 